\title{
Remembering Marina Ratner
}

\section{$\mathrm{Hee} \mathrm{Oh}$}

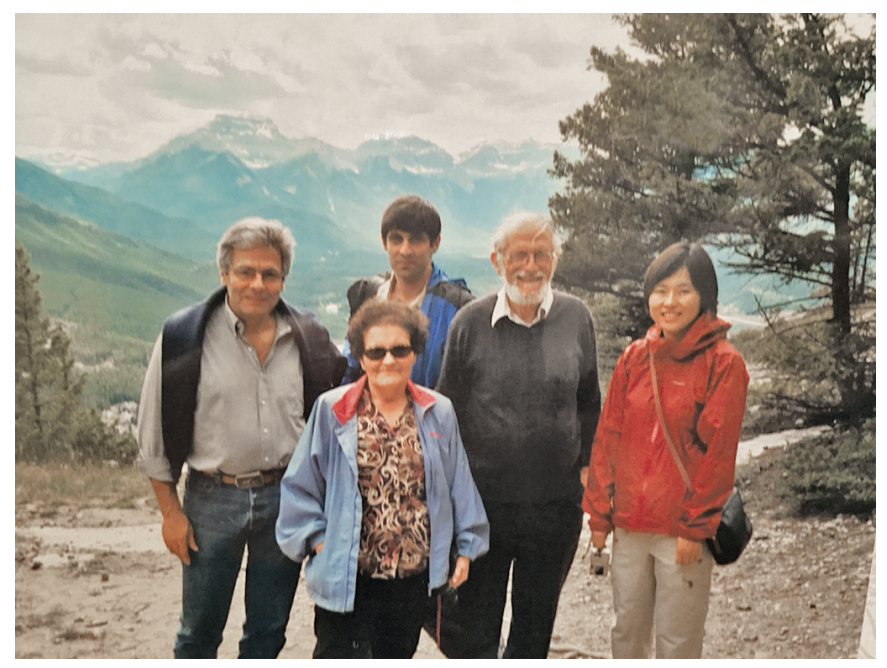

Ratner with (left to right) François Ledrappier, Dmitry Kleinbock, Hillel Furstenberg, and Oh, 2005.

I first met Marina at the International Conference on Lie Groups and Ergodic Theory held at TIFR in Mumbai in January of 1996. I was a fourth-year graduate student working with Gregory Margulis.

She gave a talk on the p-adic and $S$-arithmetic generalizations of her earlier proof of Raghunathan's conjecture. I remember how she began her talk with the assertion that while some notations and definitions may be standard, she still needed them to know for herself what she was talking about. She then went on to spend quite a big chunk of her time introducing a long list of notations and basic definitions, such as Ad-unipotents and $p$-adic Lie algebras. At the time, her talk was too technical for me to follow, but her uncompromising style left a strong impression on me.

My own lecture was about my ongoing thesis work on the arithmeticity of discrete subgroups in a higher rank simple Lie group generated by lattices in a pair of

Hee Oh is Abraham Robinson Professor of Mathematics at Yale University. Her email address is hee. oh@yale. edu.

For permission to reprint this article, please contact: reprint -permission@ams .org.

DOI: http://dx.doi.org/10.1090/noti1834 opposite horospherical subgroups, which was a conjecture of Margulis based on Selberg's earlier work in the case of a product of $S L(2, \mathbb{R})$ s. I had solved this conjecture for discrete subgroups of $\operatorname{SL}(n, \mathbb{R})$ for $n \geq 4$. Ratner's theorem on orbit closures was a key ingredient of my proof. I did not get to receive any comments from her either on my talk or on my work at that time.

Seventeen years later in 2013, there was a conference in her honor titled "Homogenous Dynamics, Unipotent Flows, and Applications" at the Hebrew University. I had just finished my joint work with Amir Mohammadi on the classification of joining measures for geometrically finite subgroups of $\operatorname{SL}(2, \mathbb{R})$ or of $\operatorname{SL}(2, \mathbb{C})$. It was an extension of her work "Horocycle flows, joining and rigidity of products," published in Annals of Mathematics 1983, and our approach was to adapt her proof in the infinite-volume setting. I opened my lecture saying that I was proud of my mathematical aunt; she and Margulis shared a common advisor, Sinai. I then successfully squeezed the two subjects of discrete groups and joinings into my one-hour lecture and closed with the statement that I had started my mathematical career by applying Ratner's theorem as a black box and that I was now hoping to generalize her ideas in the infinite-volume setting. After my lecture, I asked Marina directly, "Did you like my lecture?" She said, "Yes, very much," with a big emphasis on "very," and asked, "Why don't you post your lecture notes in your webpage?" I jokingly replied to her, "Marina, who is going to read it?"

She once said in an email to me, "If a woman is good in math, she does not need encouragement or a role model. I remember when I was young, no matter what anyone would say, I knew that I would go to math. I did not need any encouragement for that. The same is probably true about you. Did you need encouragement?"

I wrote back, saying, "Marina, whether you wanted to or not, you have been a great source of pride and inspiration for female mathematicians in the area. I am very grateful to you for having been such a great role model."

Thank you Marina.

\section{Credits}

Photo is courtesy of Nimish A. Shah. 